\title{
Developing Web-Based 3D Health-Aware Routing for Pedestrians and Cyclists
}

\author{
Rosanny Sihombing ${ }^{1 *}$, Sabo Kwada Sini ${ }^{1}$, Matthias Fitzky ${ }^{1}$ \\ ${ }^{1}$ University of Applied Sciences Stuttgart, Faculty Geomatics, Computer Science and Mathematics, Schellingstr. 24, 70174 \\ Stuttgart, Germany
}

\begin{abstract}
As the population of people migrating to cities keeps increasing, concerns have been raised about air quality in cities and how it impacts everyday life. Thus, it is important to demonstrate ways of avoiding polluted areas. The approach described in this paper is intended to draw attention to polluted areas and help pedestrians and cyclists to achieve the lowest possible level of air pollution when planning daily routes. We utilise real-time air quality data which is obtained from monitoring stations across the world. The data consist of the geolocation of monitoring stations as well as index numbers to scale the air quality level in every corresponding monitoring stations. When the air quality level is considered having a moderate health concern for people with respiratory disease, such as asthma, an alternative route that avoid air pollution will be calculated so that pedestrians and cyclists can be informed. The implementation can visualize air quality level in several areas in 3D map as well as informs health-aware route for pedestrian and cyclist. It automatically adjusts the observed air quality areas based on the availability of monitoring stations. The proposed approach results in a prototype of a health-aware 3D navigation system for pedestrian and cyclist.
\end{abstract}

\section{Introduction}

As the population of people migrating to cities keeps increasing, concerns have been raised about air quality in cities and how it impacts everyday life. Statistics show polluted air has been responsible for the death of millions of people around the world which made the WHO classify air pollution as the "world's largest single environmental health risk" [1].

Research has shown that pedestrians and cyclists are the most affected group by the effect of low air quality because they are at the receiving end of vehicles and industrial emission as they go about their normal daily activities [2]. Thus, with a constant increase in the urban population, there is a need to find a solution to avoid the harmful effect of air pollution due to growth in population and industrial activities.

As cities collect sensor data for environmental management, this data can be used to create solutions that give residents access to real-time air quality information. Furthermore, air quality data is often freely available to the public as open data which means it can be used, republished and processed to be valuable information for numerous purposes. When data is transformed into information and then into knowledge, it helps people in making better decisions [3] in many areas of life [4].

Similar research has been made to give pedestrians and cyclist alternative routes that avoid polluted areas using open data and tools [5]. However, this study does not take threedimensional (3D) navigation into account, that is preferable for self-orientation and recognizing pedestrians surroundings which in turn helps them to make better navigation decisions [6]. Furthermore, another study [7] also found it easier for people to recognize objects in $3 \mathrm{D}$ navigation and interaction in comparison to $2 \mathrm{D}$.

The virtual globe, a representation of the earth in $3 \mathrm{D}$, is changing the way we interact with spatial

\footnotetext{
Corresponding author: rosanny.sihombing@hft-stuttgart.de
} 


\section{THE $9^{\text {th }}$ INTERNATIONAL SCIENTIFIC-TECHNICAL CONFERENCE “Environmental Engineering,} Photogrammetry, Geoinformatics - Modern Technologies and Development Perspectives

data [8] and it has been used for more than 1 decade to serve science and society [9]. Moreover, the recent development of virtual globe makes it possible to build spatially enabled web-based applications without requiring plugins [10]. This means end-users only need a browser and internet connection, if it is required to pull the data, to run the application without having to install anything.

This paper aims to study how air quality open data could be used to draw attention to polluted areas and help pedestrians and cyclists in making an informed decision as they daily commute around the city and directly exposed to the polluted air which is risky to human health. If successfully implemented, the quality of life for individual would increase and the number of air pollution related diseases could be reduced.

The rest of this paper is organized as follows. Section 2 describes our approach to processed the real-time air quality data and a case study as a proof of concept is presented in Section 3. Section 4 discusses our findings from this study. Section 5 concludes this paper and highlight future works.

\section{Approach}

Main components of our approach are air quality data, a routing service and $3 \mathrm{D}$ globe since we would like to focus our work on 3D geovisualisation.

\subsection{Air Quality Data}

To know the air quality condition of a city, we use real-time air quality data from The World Air Project [11] obtained from monitoring stations across the world. The data consist of the geolocation of monitoring stations as well as Air Quality Index (AQI) which represents the measurement of air pollutants such as PM2.5 (fine particulate matter), PM10 (respirable particulate matter), $\mathrm{NO}_{2}$ (nitrogen dioxide), $\mathrm{SO}_{2}$ (sulfur dioxide), $\mathrm{CO}$ (carbon monoxide) and $\mathrm{O}_{3}$ (ozone). The AQI scales from 0 (good) to 500 (hazardous) to measure the air quality level in each monitoring station. Table 1 shows the AQI scale and its health implications on each air pollution level.

Usually, there is more than one air monitoring station in a city and they are spread across the city to measure the air pollution level in some particular areas. While the geolocations of the monitoring stations are provided, to the best of our knowledge the measurement distance range of each monitoring station is not. This range is necessary in order to know whether or not a particular area is air polluted. Therefore, we define a bounding box around each station which mark its range of measurement as illustrated in figure 1 , where $d$ is the distance from a corner point to a monitoring station.

Table 1. Air Quality Index scale of The World Air Project [11].

\begin{tabular}{|c|c|c|}
\hline AQI & $\begin{array}{c}\text { Air Pollution } \\
\text { Level }\end{array}$ & Health Implications \\
\hline $0-50$ & Good & $\begin{array}{l}\text { Air quality is considered } \\
\text { satisfactory, and air pollution } \\
\text { poses little or no risk. }\end{array}$ \\
\hline $51-100$ & Moderate & $\begin{array}{l}\text { Air quality is acceptable; } \\
\text { however, for some pollutants } \\
\text { there may be a moderate health } \\
\text { concern for a very small } \\
\text { number of people who are } \\
\text { unusually sensitive to air } \\
\text { pollution. }\end{array}$ \\
\hline $101-150$ & $\begin{array}{l}\text { Unhealthy for } \\
\text { Sensitive } \\
\text { Groups }\end{array}$ & $\begin{array}{l}\text { Members of sensitive groups } \\
\text { may experience health effects. } \\
\text { The general public is not likely } \\
\text { to be affected. }\end{array}$ \\
\hline $151-200$ & Unhealthy & $\begin{array}{l}\text { Everyone may begin to } \\
\text { experience health effects; } \\
\text { members of sensitive groups } \\
\text { may experience more serious } \\
\text { health effects. }\end{array}$ \\
\hline $201-300$ & $\begin{array}{c}\text { Very } \\
\text { Unhealthy }\end{array}$ & $\begin{array}{l}\text { Health warnings of emergency } \\
\text { conditions. The entire } \\
\text { population is more likely to be } \\
\text { affected. }\end{array}$ \\
\hline $300+$ & Hazardous & $\begin{array}{l}\text { Health alert: everyone may } \\
\text { experience more serious health } \\
\text { effects. }\end{array}$ \\
\hline
\end{tabular}

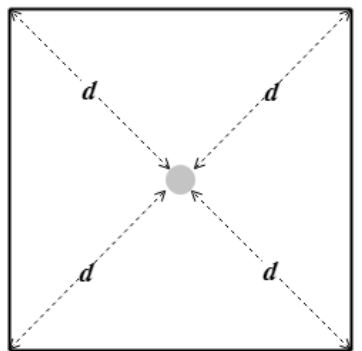

Figure 1. An illustration of the measurement distance of an air monitoring station.

\subsection{Routing Service}

Since developing a new routing algorithm is not the focus of our study presented in this paper, we decided to use an existing routing and navigation 
THE $9^{\text {th }}$ INTERNATIONAL SCIENTIFIC-TECHNICAL CONFERENCE “Environmental Engineering, Photogrammetry, Geoinformatics - Modern Technologies and Development Perspectives

service to calculate the routes. The main considerations of choosing the service are its flexibility in working with various programming languages and data format and its ability to avoid user-defined areas when calculating the routes. This consideration will make sure the service can be used along with air quality open data to provide alternative routes for pedestrians and cyclists.

Even though the air quality level with $51-100$ (moderate) AQI is acceptable, it may still affect small group of people. Therefore, when the AQI of PM2.5 in a particular area is at least 51, both common shortest route and an alternative route that avoid the area should be computed and suggested so that pedestrians and cyclists have an option to avoid the polluted area.

\subsection{Data Visualisation}

Visualising the data is how the processed data and the alternative routes are presented to end-users in a web browser. Figure 2 shows the main components and the data flow to do the visualisation. As numbered in figure 2, the steps can be explained as the following:

1) Air quality data is pulled from all monitoring stations and a bounding box is defined around each monitoring station, to mark the observed area so that end-users can see the current situation. 2a) Users define the starting and destination points by entering them in the web browser.

2b) The system then will pass the geolocations previously defined by users to the routing service so that the routing calculation can be performed.

3) Upon getting a list of manoeuvres from the routing service to reach the destination from a starting point, the manoeuvres will be drawn as the route on the $3 \mathrm{D}$ globe on the web browser. If the route is passing an area which its AQI is greater than 51 , then an alternative route that avoids the air polluted area should be calculated.

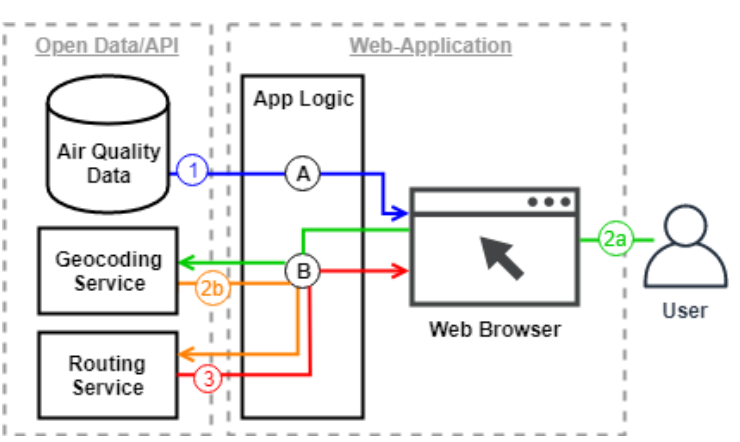

Figure 2. System architecture.

\section{Case Study}


THE $9^{\text {th }}$ INTERNATIONAL SCIENTIFIC-TECHNICAL CONFERENCE “Environmental Engineering, Photogrammetry, Geoinformatics - Modern Technologies and Development Perspectives

To demonstrate our concept, we implement a proof 
THE $9^{\text {th }}$ INTERNATIONAL SCIENTIFIC-TECHNICAL CONFERENCE "Environmental Engineering, Photogrammetry, Geoinformatics - Modern Technologies and Development Perspectives

of concept web application using Stuttgart 
THE $9^{\text {th }}$ INTERNATIONAL SCIENTIFIC-TECHNICAL CONFERENCE “Environmental Engineering, Photogrammetry, Geoinformatics - Modern Technologies and Development Perspectives

(Germany) real-time air quality data and CesiumJS 
THE $9^{\text {th }}$ INTERNATIONAL SCIENTIFIC-TECHNICAL CONFERENCE "Environmental Engineering, Photogrammetry, Geoinformatics - Modern Technologies and Development Perspectives

[12], an open source JavaScript library to create the 
THE $9^{\text {th }}$ INTERNATIONAL SCIENTIFIC-TECHNICAL CONFERENCE “Environmental Engineering, Photogrammetry, Geoinformatics - Modern Technologies and Development Perspectives

3D globe. For calculating the routes, we use the

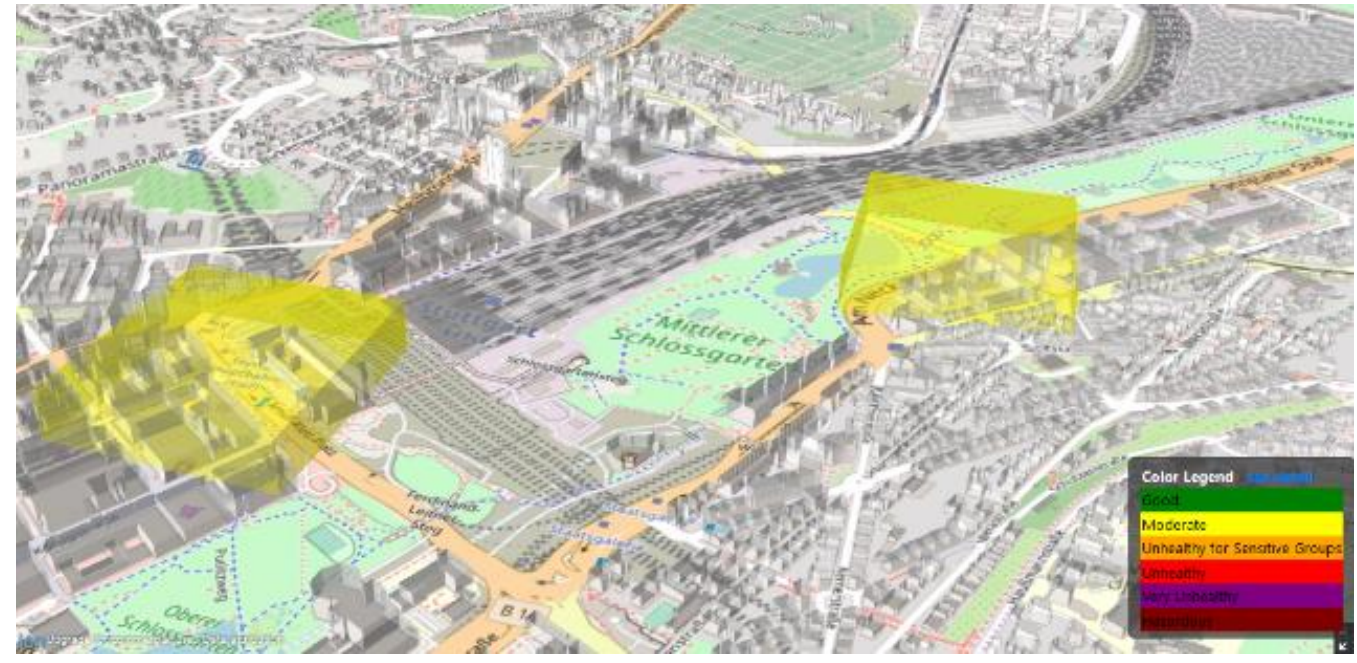

Figure 4. A closer look of observed areas. The colour indicates the air pollution level while the height indicates the air quality index. 
THE $9^{\text {th }}$ INTERNATIONAL SCIENTIFIC-TECHNICAL CONFERENCE “Environmental Engineering, Photogrammetry, Geoinformatics - Modern Technologies and Development Perspectives

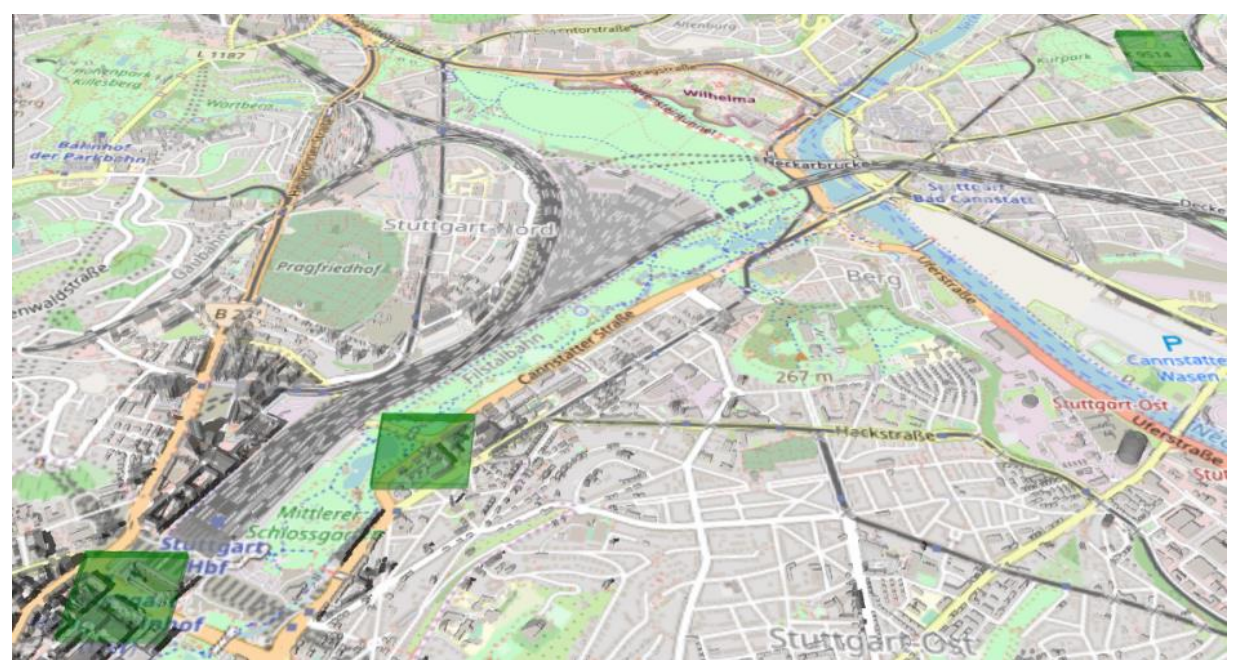

Figure 3. Three air quality observed areas in Stuttgart city centre. Green bounding box indicates the air quality is currently in "Good" level (AQI = 0-50).

routing and navigation service provided by HERE Technologies [13].

With the help of such governmental enforcement, the portion of nitrogen-oxide in German cities has been kept low compared to other countries. Due to its geographical location in a valley basin [14] and other environmental factors, Stuttgart has been known to have low air quality compared to other cities in Germany. The local government has been actively working [15] on improving the air quality as an effort to suppress harmful consequences for people's health. Since 2016 Stuttgart has a public air pollution alert called Fine Dust Alarm [16], which will be triggered when the German Meteorological Service (DWD) forecasts particular limitations in atmospheric airflow on at least two consecutive days between 15 October and 15 April. When there is a fine dust alert, the City of Stuttgart will reduce the public transport ticket price to encourage the residents to use their cars as little as possible and commute with public transport. In a more recent event, vehicles running on diesel fuel may no longer enter the environmental zone of Stuttgart starting from 1 January 2019 [17].

To observe the air pollution in Stuttgart for our case study, we utilise real-time air quality data obtained from air monitoring stations across the world [11]. The hourly data in Stuttgart can be accessed anytime through an Application Programming Interface (API) and it has JavaScript Object Notation (JSON) format, a lightweight datainterchange format. There are 3 air monitoring stations across Stuttgart which are located in the following places:

1. Arnulf-Klett-Platz (Lat: 48.7831171; Long: 9.1791276)

2. Am Neckartor (Lat: 48.7873895; Long:

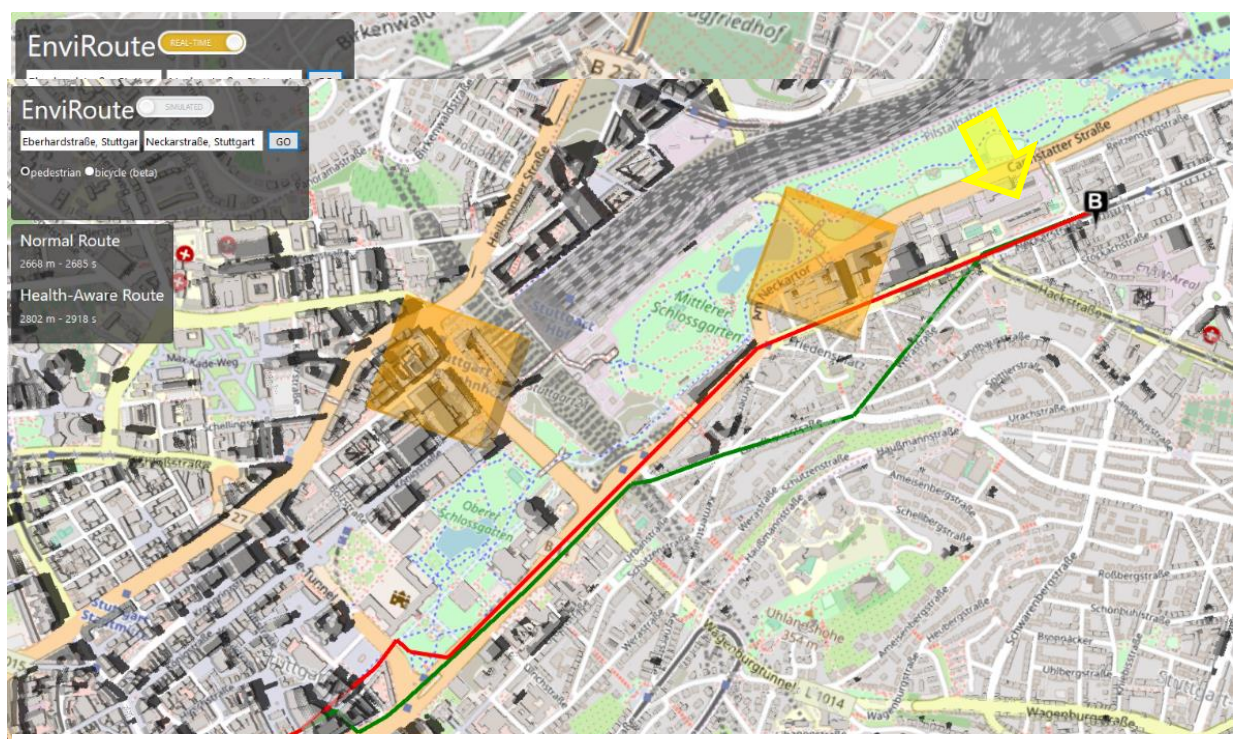

Figure 6. Two different routes to reach Neckarstraße (B) from Eberhardstraße (A) when the air is polluted.

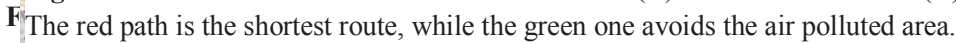
a) 
THE $9^{\text {th }}$ INTERNATIONAL SCIENTIFIC-TECHNICAL CONFERENCE “Environmental Engineering, Photogrammetry, Geoinformatics - Modern Technologies and Development Perspectives

9.1876753)

3. Bad Cannstatt (Lat: 48.8078341; Long: 9.2012528)
Figure 7 shows another route scenario (Eupener Straße - Tilsiter Straße) where pedestrians walk through an observed area to reach the destination

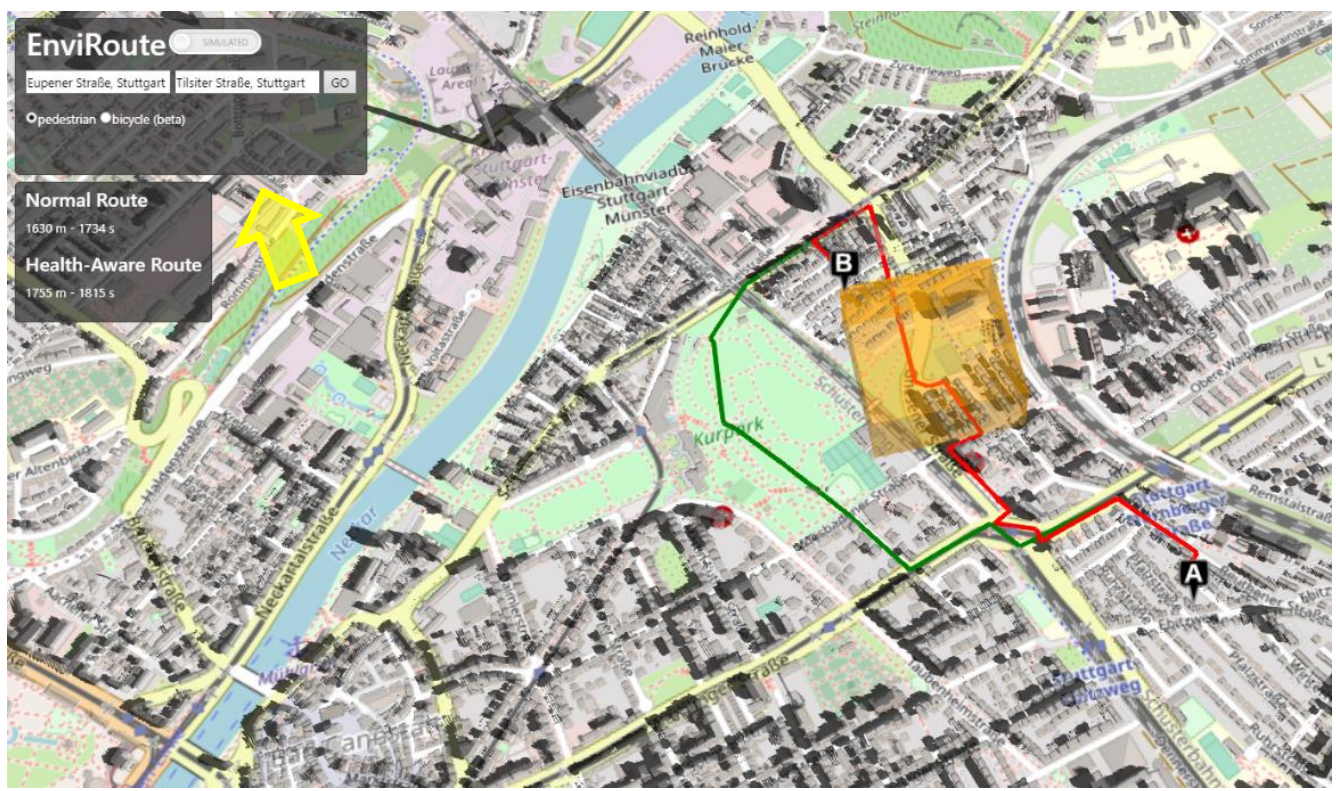

Figure 7. Routes from Eupener Straße (A) to Tilsiter Straße (B) when pedestrians have to walk through a polluted area if taking the shortest route.

As shown in figure 3 and figure 4, a bounding box is constructed on each monitoring station to mark the observed area. Its corners are meters from the station and calculated using a JavaScript library explained in [18]. The height of the bounding box represents the AQI and the col ir :epresents the air quality level which also correspin to a particular health implication as shown in table 1 .

To see how our approach works, we choose two different routes where the shortest route to reach a destination suggest pedestrians and cyclist to pass at least 1 observed area. We then compare the distance between common shortest routes and alternative routes that takes air pollution into account.

Figure 5 and figure 6 show the same route scenario (from Eberhardstraße to Neckarstraße) where pedestrians must walk through an observed area if they want to take the shortest route. Furthermore, figure 5 shows the condition where the air quality poses little or no risk, while the air pollution in figure 6 is unhealthy for people with respiratory disease (AQI $=101-150)$. Therefore, figure 5 only shows the shortest route and suggest no alternative route, while figure 6 shows the shortest route and also an alternative route that avoids a polluted area to reach the destination. when they take the shortest path. Similar to figure 6 , an alternative route that avoids air pollution appears on the system since the air pollution in the observed area is considered unhealthy. For the cyclist experiments, the same route scenarios are used. As pictured in figure 8 below, alternative routes are given to cyclists because of unhealthy air quality so that they can avoid polluted area.

Table 2 presents two route scenarios for both pedestrians and cyclists, in which each row shows starting and destination location, the distance to reach destination using shortest-path algorithm $\left(d_{1}\right)$ in kilometre $(\mathrm{km})$, the distance of the same route that takes air pollution into account $\left(d_{2}\right)$, and the $\mathrm{d}$, viation (dev) percentage between $d_{l}$ and $d_{2}$.

Table 2. Experimental data

\begin{tabular}{|c|c|c|c|c|}
\hline \multicolumn{2}{|r|}{ Route } & $d_{1}(\mathrm{~km})$ & $d_{2}(\mathrm{~km})$ & $\operatorname{dev}(\%)$ \\
\hline \multirow{2}{*}{ 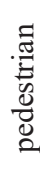 } & $\begin{array}{l}\text { Eberhardstraße - } \\
\text { Neckarstraße }\end{array}$ & 2,67 & 2,8 & 5 \\
\hline & $\begin{array}{l}\text { Eupener Straße - } \\
\text { Tilsiter Straße }\end{array}$ & 1,63 & 1,76 & 8 \\
\hline \multirow{2}{*}{$\frac{\vec{n}}{\frac{\vec{n}}{0}}$} & $\begin{array}{l}\text { Eberhardstraße - } \\
\text { Neckarstraße }\end{array}$ & 3,15 & 3,42 & 8,5 \\
\hline & $\begin{array}{l}\text { Eupener Straße - } \\
\text { Tilsiter Straße }\end{array}$ & 1,97 & 2,33 & 18 \\
\hline
\end{tabular}


THE $9^{\text {th }}$ INTERNATIONAL SCIENTIFIC-TECHNICAL CONFERENCE "Environmental Engineering, Photogrammetry, Geoinformatics - Modern Technologies and Development Perspectives

\section{Discussion}

Air pollution can be dangerous for pedestrians and cyclists as they breathe the air without any form of protection when they commute every day. Providing them up-to-date information about the air pollution level and alternative routes to avoid polluted areas may help to reduce their health risk. Such a solution can be provided by processing air
In this paper, the air quality open data provides the location of air monitoring stations and their respective air quality index. We then define an observed area around each monitoring station. If the air quality is giving moderate health concern for a very small number of people who are unusually sensitive to air pollution $(\mathrm{AQI}=51-100)[11]$, then an alternative pedestrian or bike route that avoids the polluted area will be presented.
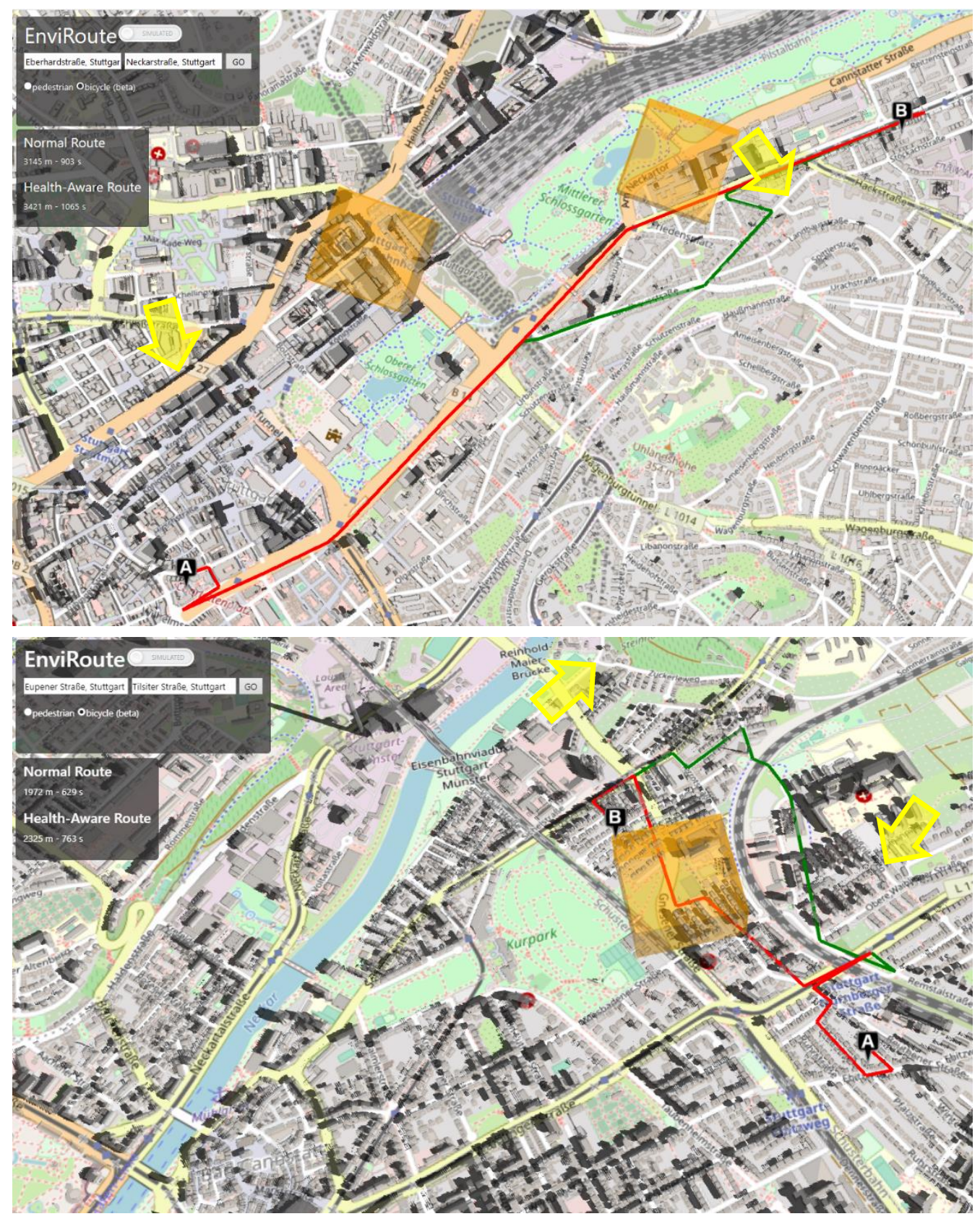

Figure 8. Red paths indicate shortest bike routes and green paths indicate health-aware bike routes. (Top) Routes from Eberhardstraße (A) to Neckarstraße (B). (Bottom) Routes from Eupener Straße (A) to Tilsiter Straße (B).

quality open data into the required information. 
THE $9^{\text {th }}$ INTERNATIONAL SCIENTIFIC-TECHNICAL CONFERENCE “Environmental Engineering, Photogrammetry, Geoinformatics - Modern Technologies and Development Perspectives

The case study shows the proposed approach is capable to show air polluted areas and suggests an alternative route to avoid the areas by utilizing open data and tools. In pedestrians category, the suggested alternative routes are less than only $10 \%$ farther compared to the shortest routes. In cyclists category, an alternative route in one case is also less than $10 \%$ farther but $18 \%$ farther in the other case because of the limited number of bike paths in the case study area. Once a bike path is air polluted, cyclists are suggested to take another path which can cost them the distance and travel time.

The open data we use on the case study is wellformatted and can be easily accessed through an API. These aspects play important roles in extracting and processing the data so it can be presented as meaningful information and make the implementation relatively flexible and straightforward. For example, if new air monitoring stations are added to the open data source, as long as the data format and structure stay the same, there should be no further action needed to modify the implementation codes in order to accommodate the new stations because even though the iteration to extract the data will be longer, the mechanism stays the same.

Due to a limited number and coverage of air quality sensor data in our case study, it does not mean the alternative routes are healthier than the avoided areas because the computation is made by avoiding the areas with available air quality sensor data. This means even though the air polluted areas can be avoided, unless the whole area is covered by air quality data, there is no guarantee the alternative routes on the case study is less polluted. Therefore, to have a more optimal computation of the alternative routes, there is a need to have a fair distribution of air quality sensors across the study area so that an air pollution level comparison among all areas data can be performed.

As our approach focus on 3D, it should be possible to complement the data with $3 \mathrm{D}$ building model data as it could contain environmental related data, such as building heat demand. Buildings could also be on renovations and making dust from the building renovation or construction that is harmful for pedestrians with respiratory disease.

\section{Conclusion}

When utilised in a suitable use case, open data can be made not only relevant in daily life but also could improve quality of life. In this paper, the data is used to draw people attention which helps in making a daily decision that could impact people health in the long term.

As mentioned earlier, the number of air quality sensors used for the case study in this paper is not fairly distributed across the study area. Therefore, an alternative data source that has more coverage would be taken into account in future work. Moreover, it is also our interest to integrate more health aware data, such as pollen for people with pollen allergies [19], as the current system continues to evolve.

Another current limitation to be addressed in the future work is a lack of information concerning air pollution range and distribution. This is important because it will help in setting a more accurate bounding box or circle around the polluted area instead of assuming its range and distribution. The information range, distribution pattern and type of pollution is important to assign boundaries and determine the rate at which the polluted air travels to nearby areas.

\section{Acknowledgements}

Publication is funded by the Polish National Agency for Academic Exchange under the International Academic Partnerships Programme from the project „Organization of the 9th International Scientific and Technical Conference entitled Environmental Engineering, Photogrammetry, Geoinformatics - Modern Technologies and Development Perspectives".

\section{References}

[1] World Health Organization, "World Health Organization releases 7 million premature deaths annually linked to air pollution," 2014. [Online]. Available: http://www.who.int/mediacentre/news/releases /2014/air-pollution/en/. [Accessed: 30-Nov2019].

[2] P. Kumar, I. Rivas, A. P. Singh, V. J. Ganesh, M. Ananya, and H. C. Frey, "Dynamics of coarse and fine particle exposure in transport microenvironments," npj Clim Atmos Sci 1, 11, 2018.

[3] L. B. Ayre and J. Craner, "Open Data: What It 
THE $9^{\text {th }}$ INTERNATIONAL SCIENTIFIC-TECHNICAL CONFERENCE “Environmental Engineering, Photogrammetry, Geoinformatics - Modern Technologies and Development Perspectives

Is and Why You Should Care," Public Libr. Q., 2017.

[4] Open Knowledge Foundation, "Why Open Data?" [Online]. Available: https://opendatahandbook.org/guide/en/whyopen-data/. [Accessed: 30-Nov-2019].

[5] S. Müller and A. Voisard, "Air quality adjusted routing for cyclists and pedestrians," in Proceedings of the 1st ACM SIGSPATIAL International Workshop on the Use of GIS in Emergency Management, EM-GIS 2015, 2015, pp. 1-6.

[6] T. Aditya, D. Laksono, H. Sutanta, N. Izzahudin, and F. Susanta, "A USABILITY EVALUATION OF A 3D MAP DISPLAY FOR PEDESTRIAN NAVIGATION," ISPRS - Int. Arch. Photogramm. Remote Sens. Spat. Inf. Sci., vol. XLII-4/W10, pp. 3-10, 2018.

[7] L. Herman and T. Řezník, "3D WEB VISUALIZATION OF ENVIRONMENTAL INFORMATION - INTEGRATION OF HETEROGENEOUS DATA SOURCES WHEN PROVIDING NAVIGATION AND INTERACTION," ISPRS - Int. Arch. Photogramm. Remote Sens. Spat. Inf. Sci., vol. XL-3/W3, pp. 479-485, 2015.

[8] D. Butler, "The web-wide world," Nature, vol. 439 , no. 7078, pp. 776-778, 2006.

[9] T. Blaschke et al., "Virtual globes: Serving science and society," Inf., vol. 3, no. 3, pp. 372-390, 2012.

[10] Khronos, "WebGL - OpenGL ES 2.0 for the Web," 2012. [Online]. Available: http://www.khronos.org/webgl/.

[11] The World Air Quality Project, "Air Quality Index," 2019. [Online]. Available: https://aqicn.org. [Accessed: 30-Nov-2019].

[12] Cesium, “Open Source 3D Mapping,” 2019. [Online]. Available: https://cesium.com/cesiumjs. [Accessed: 30Nov-2019].

[13] HERE Technologies, "Build apps with HERE Maps API and SDK Platform Access," 2019. [Online]. Available: https://developer.here.com. [Accessed: 30Nov-2019].
[14] Municipality of Stuttgart, "Stuttgart: combating the heat island effect and poor air quality with green ventilation corridors," 2014. [Online]. Available: https://climateadapt.eea.europa.eu/metadata/casestudies/stuttgart-combating-the-heat-islandeffect-and-poor-air-quality-with-greenventilation-corridors. [Accessed: 30-Nov2019].

[15] City of Stuttgart, "Clean air plan Stuttgart," 2019. [Online]. Available: https://www.stadtklimastuttgart.de/index.php?air_clean_air_plan_stgt . [Accessed: 30-Nov-2019].

[16] Landeshauptstadt Stuttgart, "Information about the Feinstaubalarm," 2019. [Online]. Available: https://www.stuttgart.de/en/en/feinstaubalarm. [Accessed: 30-Nov-2019].

[17] Landeshauptstadt Stuttgart, "Information on the traffic ban for diesel vehicles," 2019. [Online]. Available: https://www.stuttgart.de/en/diesel-ban. [Accessed: 30-Nov-2019].

[18] C. Veness, "Calculate distance, bearing and more between Latitude/Longitude points," 2019. [Online]. Available: http://www.movabletype.co.uk/scripts/latlong. html. [Accessed: 30-Nov-2019].

[19] T. Santhanavanich, P. Würstle, and G. Baumann, "Smart Pollen Monitoring: The Web-based Application for Monitoring TreePollen," in Applied Geoinformatics for Society and Environment, 2019. 